\title{
Integrated extraction and catalytic upgrading of microalgae lipids in supercritical carbon dioxide $\uparrow$
}

\author{
Julia Zimmerer, (D) Dennis Pingen, (D) Sandra K. Hess, (D) Tobias Koengeter (D) and \\ Stefan Mecking (ID *
}

\begin{abstract}
Fatty acids from microalgae are attractive compounds for catalytic upgrading to chemicals, but their extraction often requires multi-step procedures and the use of various organic solvents. To relieve this bottleneck, we propose a straightforward approach of combined extraction and catalytic functionalization via olefin cross-metathesis (ethenolysis and butenolysis) in supercritical $\mathrm{CO}_{2}\left(\mathrm{scCO}_{2}\right)$. This is demonstrated for Phaeodactylum tricornutum microalgae biomass. $\mathrm{ScCO}_{2}$ at optimum conditions $\left(90{ }^{\circ} \mathrm{C}, 620\right.$ atm, $\left.\rho\left(\mathrm{CO}_{2}\right)=0.90 \mathrm{~g} \mathrm{~mL}^{-1}\right)$ extracted the lipids selectively and quantitatively from previously disrupted cells, while organic solvent extraction for comparison additionally extracted polar diacylglycerides and chlorophylls. In a one-pot approach, olefin cross-metathesis of the unsaturated fatty acids (FA16:1, FA18:1 and FA20:5) by alkenolysis yielded the desirable mid-chain olefin and unsaturated ester products. The product spectrum compares to alkenolysis of individual model compounds in $\mathrm{scCO}_{2}$ as well as of separately $\mathrm{scCO}_{2}$ extracted microalgae oil. Both these ethenolysis and butenolysis proceed with conversions of more than $81 \%$ and high selectivities to the desired products. This biorefinery approach was further illustrated by the simultaneous extraction and catalytic isomerizing alkoxycarbonylation in $\mathrm{scCO}_{2}$.
\end{abstract}

\section{Introduction}

Microalgae are a promising future feedstock. Unlike traditional crops like soy, palms or sunflowers they do not require arable land. Also, per acre yields can be much higher. Microalgae can be cultivated in fresh, salt or brackish water. ${ }^{1}$ Autotrophically or heterotrophically grown microalgae are an established source of high value food additives and pigments. Further, the production of fuels from microalgae oils has been demonstrated on a multiton scale. By comparison to fuels, a production of higher value chemicals would appear more sensible. ${ }^{2,3}$ Unlike fuel production, which downgrades the plant oil feedstock to hydrocarbons, the production of chemicals can take advantage of the particular molecular structure of the feedstock. Notably, microalgae oils can contain unique fatty acids with unusual chain lengths and multiple double bonds not found in traditional plant oils. ${ }^{1,4,5}$

Yet the usage of biomass has a significant bottleneck; the isolation of the desired substrates and extraction often requires energy-intensive multi-step procedures and the use of

Chair of Chemical Materials Science, Department of Chemistry,

University of Konstanz, 78464 Konstanz, Germany.

E-mail: stefan.mecking@uni-konstanz.de; Fax: +49 7531 88-5152;

Tel: $+49753188-5151$ environmentally harmful organic solvents. This also applies to microalgae, where the achievable cell densities are limited. To address this problem, we pursue an integration of the biomass extraction with the catalytic upgrading in a common solvent, supercritical carbon dioxide ( $\mathrm{scCO}_{2}$. Fig. 1).

Advantageously, $\mathrm{scCO}_{2}$ is capable of the selective extraction of lipids from microalgae ${ }^{6-11}$ and various catalytic reactions of interest have been reported to be compatible with $\mathrm{scCO}_{2}$ as a solvent. ${ }^{12-16}$ Additionally, $\mathrm{scCO}_{2}$ is non-toxic, non-flammable and it can be easily removed. For the upgrading of palm oil, alkenolysis is an established reaction. ${ }^{17}$ Considering microalgae oils as a feedstock, alkenolysis of their unconventional

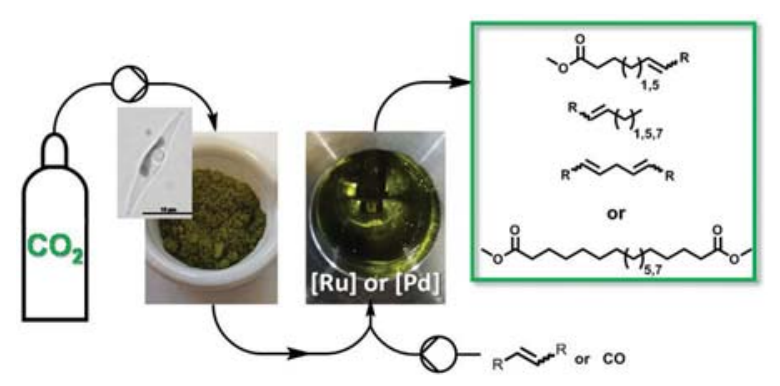

Fig. 1 Schematic process design of extraction and catalytic valorization of microalgae in $\mathrm{scCO}_{2}$ to mid-chain olefins, unsaturated esters and long-chain $\alpha, \omega$-diesters. 
fatty acids (vide supra) can provide a range of useful compounds, difficult to access otherwise. ${ }^{18}$ In literature ruthenium-based olefin metathesis has been reported to be compatible with $\mathrm{ScCO}_{2} \cdot{ }^{19-21}$

\section{Results and discussion}

\section{Extraction and characterization of algae oil from Phaeodactylum tricornutum}

We employed Phaeodactylum tricornutum for our studies, as this algae strain is robust and can contain high amounts of unsaturated fatty acids. ${ }^{22}$ To find suitable extraction conditions, $1 \mathrm{~g}$ of freeze-dried algae (harvested in the late stationary phase) was subjected to $\mathrm{scCO}_{2}$ extraction at different pressures and temperatures, and thus also different densities ${ }^{23}$ (Table S2 and Fig. S6 in the ESI†).

At a given density, the efficiency of extraction as reflected by the yield of algae oil increases with increasing extraction temperatures. The extraction pressure is often the technically limiting factor, given by the equipment employed. Notably, for a given pressure, the yield increases with increasing temperature, even though the $\mathrm{scCO}_{2}$ density decreases. Disruption of the microalgae cells by ultrasonication ${ }^{24,25}$ (Fig. S4 $\dagger$ ) prior to extraction enhanced yields by $c a .20 \%$ to $30 \%$. Under the optimum conditions of the range investigated, $90{ }^{\circ} \mathrm{C}$ and 621 bar corresponding to $\rho=0.9 \mathrm{~g} \mathrm{~mL}^{-1}, 25 \mathrm{wt} \%$ yield of algae oil were obtained (Fig. 2).

As a reference, an algae sample was extracted with organic solvent using a mixture of water, methanol and chloroform ( $3: 4: 8)$, as described by Folch. ${ }^{26}$ This method, which quantitatively captures all fatty acid compounds present in the microalgae, yielded $28 \mathrm{wt} \%$ of extracted algae oil.

Gas chromatographic (GC) analysis of the extracted oils reveals similar fatty acid compositions, largely independent of the $\mathrm{scCO}_{2}$ extraction conditions (Fig. 3). With only small variations ( $c$. $2 \%$ ), $55 \%$ of mono-unsaturated fatty acids ( $47 \%$ palmitoleic acid (FA16:1) and 8\% oleic acid (FA18:1)), 10\% of the

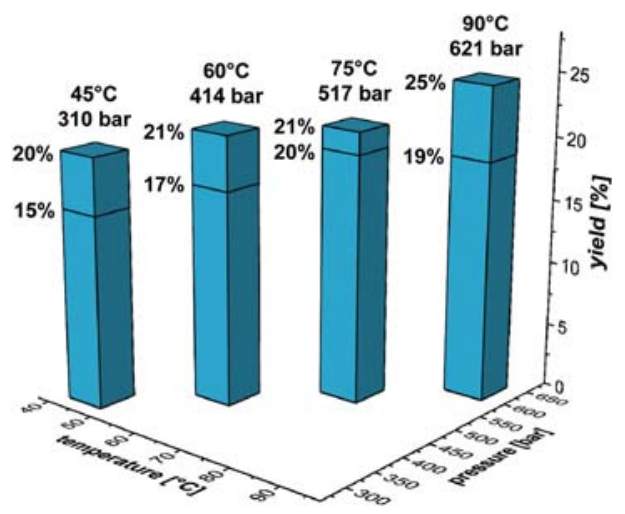

Fig. 2 Yields of $\mathrm{scCO}_{2}$ extraction at different pressures and temperatures at constant density $\left(0.9 \mathrm{~g} \mathrm{~mL}^{-1}\right)$. Lower part of the bar: extraction of freeze-dried algae, lower and upper part of the bar: extraction of ultrasound pre-treated freeze-dried algae.

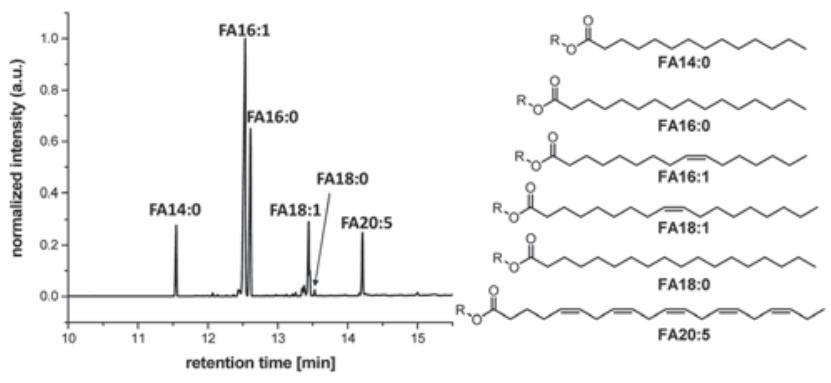

Fig. 3 Gas chromatogram of $\mathrm{SCCO}_{2}$ extracted algae oil from Phaeodactylum tricornutum (after transesterification with methanol for GC analysis). Myristic acid methyl ester FA14:0 9\%, palmitoleic acid methyl ester FA16:1 47\%, palmitic acid methyl ester FA16:0 25\%, oleic acid methyl ester FA18:1 8\%, stearic acid methyl ester FA18:0 <1\%, eicosapentaenoic acid methyl ester FA20:5 10\%.

multiple unsaturated fatty acid eicosapentaenoic acid (FA20:5), and $35 \%$ of saturated fatty acids $(<1 \%$ stearic acid (FA18:0), 25\% palmitic acid (FA16:0) and 9\% myristic acid (FA14:0)) are present. In total the algae oil extracted by means of $\mathrm{scCO}_{2}$ contains around $4 \mathrm{mmol}$ of double bonds per 1 gram of oil, as quantified via an internal GC standard. By comparison, the oil extracted via the modified Folch method has a similar fatty acid profile (see Fig. $\mathbf{S} 5 \dagger$ ).

The entire composition of the extracted oils in terms of classes of compounds present was quantified by a comprehensive analysis by a combination of methods ( $c f$. ESI $\dagger$ ). The lipid composition was analyzed via thin-layer chromatography (TLC), ${ }^{27,28}$ pigments were quantified via high-performance liquid chromatography (HPLC) ${ }^{29}$ and the content of proteins and carbohydrates was determined via Fourier-transform infrared spectroscopy (FT-IR). ${ }^{30}$ Polar diacylglycerides ${ }^{31}$ and chlorophylls ${ }^{32}$ were found to not be extracted by the apolar $\mathrm{scCO}_{2}$ (Fig. S14 and S17†), in line with previous findings. ${ }^{33}$ Proteins were also not detected in the investigated oils (Fig. S14†), corresponding to a protein content below $2 \%$ (detection limit of FT-IR). Compared to the aforementioned Folch organic solvent extraction, extraction with $\mathrm{scCO}_{2}$ as a nonpolar solvent is indeed more selective for the desired triacylglycerides, and carotenoids. This is also reflected by the color of the samples (Fig. S7 $\uparrow$ ). The amount of pigments and polar diacylglycerides, which could interfere with catalysts, are $1.1 \%$ and below the detection limit ( $<5 \mathrm{wt} \%$ for TLC), respectively, for $\mathrm{scCO}_{2}$ extracted oil. By comparison, with Folch's organic solvent mixture also substantial amounts $(\sim 10 \%)$ of phospho- and glycolipids (Fig. S11 and S12 $\dagger$ ) as well as chlorophylls (Fig. S17 and $\mathrm{S} 18 \dagger$ ) are extracted from the microalgae samples (Table S8 $\dagger$ ). This accounts for the differences in yields, that is, $\mathrm{scCO}_{2}$ extraction under the conditions studied quantitatively extracts the triacylglycerides from the microalgae biomass.

\section{Ethenolysis of model compounds and microalgae oil}

Catalytic upgrading of fatty acids from microalgae via crossmetathesis gives access to a broad spectrum of unsaturated 


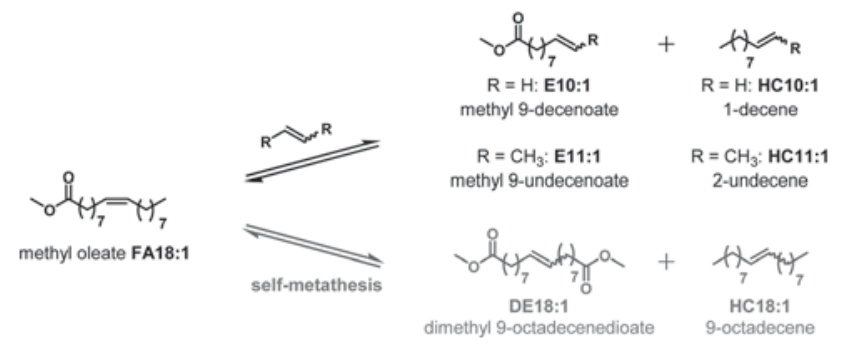

Scheme 1 Self- and cross-metathesis of methyl oleate with ethylene or 2-butene.

compounds. A general scheme of cross-metathesis of methyl oleate with ethylene or 2-butene is shown in Scheme 1.

The ethenolysis of unsaturated fatty acids in $\mathrm{scCO}_{2}$ as reaction medium was first investigated with methyl oleate as a model compound which gives methyl 9-decenoate E10:1 and 1-decene HC10:1 as the desired products (Scheme 1, R = H).

Based on the results of the $\mathrm{scCO}_{2}$ extraction of algae oil and with respect to the limited thermal stability of the metathesis catalyst, a temperature of $45^{\circ} \mathrm{C}$ and a pressure of 300 bar were chosen for all ethenolysis experiments. In accordance to Song et al.,$^{34} 1 \mathrm{~mol} \%$ of Grubbs $1^{\text {st }}$ generation catalyst was employed. With 10 bar ethylene and total pressure of 300 bar at $45{ }^{\circ} \mathrm{C}$ a conversion of $61 \%$ of methyl oleate was achieved (Table S10 $\dagger$ ). No self-metathesis products $(<1 \%)$ of methyl oleate (dimethyl 9-octadecendioate DE18:1 and 9-octadecene HC18:1, Scheme 1) were observed. Due to promising results with Hoveyda-Grubbs $1^{\text {st }}$ generation catalyst in the ethenolysis of methyl oleate in dichloromethane (Table S9†), this catalyst was also applied in the ethenolysis with $\mathrm{scCO}_{2}$ as solvent. Under the same conditions as for Grubbs $1^{\text {st }}$ generation catalyst ( $1 \mathrm{~mol} \%$ catalyst, 10 bar ethylene, 300 bar total pressure at $45{ }^{\circ} \mathrm{C}$ ), Hoveyda-Grubbs $1^{\text {st }}$ generation catalyst gave a higher conversion of $88 \%$ and again almost no self-metathesis products were observed. Based on these results, the ethenolysis in $\mathrm{ScCO}_{2}$ was further investigated with Hoveyda-Grubbs $1^{\text {st }}$ generation catalyst. The highest conversions of up to $88 \%$ were obtained using a catalyst loading of $0.5 \mathrm{~mol} \%$ or $1 \mathrm{~mol} \%$, respectively, at an ethylene pressure of 10 bar. Conversions could not be improved neither by lowering the ethylene pressure nor by increasing the reaction time (see Table S10 $\dagger$ ).

Considering an effect on the solubility of the catalyst precursor, Grubbs $1^{\text {st }}$ and $2^{\text {nd }}$ generation catalysts have been suggested to be insoluble in $\mathrm{scC}_{2}\left(40{ }^{\circ} \mathrm{C}, 140\right.$ bar corresponds to $\left.0.75 \mathrm{~g} \mathrm{~mL}^{-1}\right) .{ }^{20}$ While we cannot exclude that under our conditions a dissolution of the catalyst precursor (HoveydaGrubbs $2^{\text {nd }}$ generation catalyst, Grubbs $1^{\text {st }}$ and $2^{\text {nd }}$ generation catalyst, respectively) is assisted by reaction with the fatty acid substrate, a comparison of conversion in ethenolysis in $\mathrm{scCO}_{2}$ vs. dichloromethane as a solvent (Tables S10 and S9†) suggests that in $\mathrm{scCO}_{2}$ catalyst solubility is not an issue and a substantial portion or the entire amount of catalyst precursor is dissolved.

The ethenolysis of algae lipid feedstocks will provide a more complex spectrum of unsaturated products (Scheme 2):

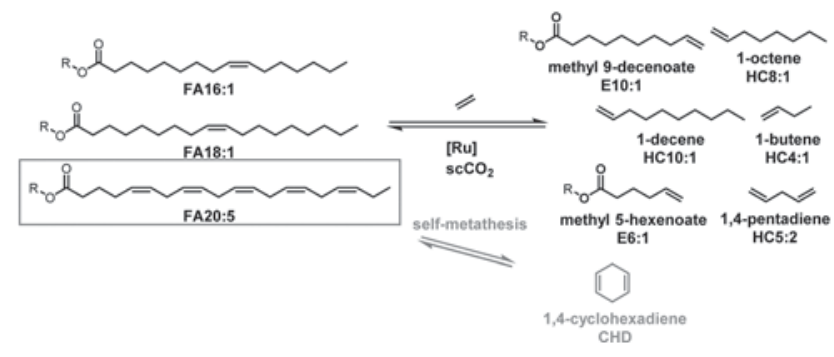

Scheme 2 Ethenolysis products of the unsaturated fatty acids present in algae oil from $P$. tricornutum, and CHD as a self-metathesis product of $\mathrm{FA} 20: 5$.

from FA16:1 and FA18:1 1-octene HC8:1, 1-decene HC10:1 and methyl 9-decenoate E10:1 is formed, whereas complete ethenolysis of FA20:5 results in 1,4-pentadiene HC5:2, methyl 5-hexenoate E6:1 and 1-butene HC4:1. Yet, 1,4-pentadiene HC5:2 and 1-butene HC4:1 could not be quantified by GC analysis due to their low boiling point. Please note, complete ethenolysis of FA20:5 can generate up to four equivalents of HC5:2. Furthermore, instead of cross-metathesis, up to two equivalents of 1,4-cyclohexadiene CHD can be generated in a selfmetathesis reaction of FA20:5. Its intramolecular nature in principle favors the latter reaction. ${ }^{35}$

To exclude any adverse effects from additional compounds present in small amounts in the algae oil besides the fatty acids (e.g. carotenoids), ethenolysis of a mixture of model compounds (40\% FA16:0 50\%, FA18:1 and 10\% FA20:5) resembling the fatty acid composition of algae oil was investigated (Table 1, column "model substrate mixture"). The conversion and selectivity for all expected reaction products were determined over FA16:0 as an internal standard via gas chromatography. The selectivity is defined as the ratio of the formed product to the theoretical maximum amount of this product at complete ethenolysis or in case of CHD (1,4-cyclohexadiene) complete self-metathesis of FA20:5 (formation of two equivalents CHD).

In accordance to the experiments with neat methyl oleate, a catalyst loading of $0.5 \mathrm{~mol} \%$ Hoveyda-Grubbs $1^{\text {st }}$ generation catalyst (referring to the number of double bonds) and $10 \mathrm{bar}$ of ethylene were chosen. After $6 \mathrm{~h}$, a high conversion of $86 \%$ for FA18:1 was observed (Table 1). This value is comparable to the conversion of neat methyl oleate as single model compound. The poly-unsaturated component FA20:5 was almost completely consumed after $6 \mathrm{~h}$.

The selectivity for the ethenolysis products of FA18:1 (HC10:1 and E10:1) was above 99\%, as also observed for the single FA18:1 compound. The ethenolysis product E6:1 of FA20:5 was also formed with a high selectivity of $85 \%$. However, the self-metathesis of FA20:5 could not be suppressed. The selectivity for the self-metathesis product 1,4cyclohexadiene CHD was $84 \%$. This suggests a higher reaction rate of the intramolecular self-metathesis leading to the formation of CHD compared to the intermolecular crossmetathesis. 
Table 1 Ethenolysis of unsaturated fatty acids of a model substrate mixture and $\mathrm{scCO}_{2}$ extracted algae oil with conversions of the components and selectivities to ethenolysis products and the self-metathesis product 1,4-cyclohexadiene (CHD)

\begin{tabular}{|c|c|c|c|}
\hline Ethenolysis of & & $\begin{array}{l}\text { Model } \\
\text { substrate } \\
\text { mixture }^{a}\end{array}$ & $\begin{array}{l}\mathrm{scCO}_{2} \\
\text { extracted } \\
\text { algae oil }\end{array}$ \\
\hline \multirow{6}{*}{$\begin{array}{l}\text { Composition of the initial reaction } \\
\text { mixture }[\%]\end{array}$} & FA14:0 & - & 9 \\
\hline & FA16:1 & - & 49 \\
\hline & FA16:0 & 40 & 27 \\
\hline & FA18:1 & 50 & 4 \\
\hline & FA18:0 & - & 2 \\
\hline & FA20:5 & 10 & 9 \\
\hline \multirow[t]{3}{*}{ Conversion $^{b}[\%]$} & FA16:1 & - & 81 \\
\hline & FA18:1 & 86 & 90 \\
\hline & FA20:5 & $>99$ & 92 \\
\hline \multirow[t]{5}{*}{ Selectivity $^{c}[\%]$ for } & CHD & 84 & 64 \\
\hline & E6:1 & 85 & 82 \\
\hline & HC8:1 & - & 83 \\
\hline & HC10:1 & $>99$ & 97 \\
\hline & E10:1 & $>99$ & 84 \\
\hline
\end{tabular}

Conditions: 0.5 mol\% Hoveyda-Grubbs $1^{\text {st }}$ generation catalyst per double bond, 10 bar ethylene, 300 bar $\mathrm{CO}_{2}$ (total pressure) at $45{ }^{\circ} \mathrm{C}$, $6 \mathrm{~h}$. Average of two independent experiments, $c f$. ESI for complete data. ${ }^{a}$ Mixture of 40\% FA16:0, 50\% FA18:1, 10\% FA20:5. ${ }^{b}$ Determined over FA16:0 as an internal standard. ${ }^{c}$ The selectivity to a product is defined as the ratio of the product to the theoretical maximum amount of this product at complete ethenolysis or in case of CHD $(1,4$ cyclohexadiene) complete self-metathesis of FA20:5 (determined over FA16:0 as an internal standard) in the gas chromatogram.

Ethenolysis of algae oil was performed applying the same reaction conditions as for the model substrate mixture. The selectivities and conversions were determined via gas chromatography (Fig. 4) over FA16:0 as internal standard, which is, besides FA14:0, found as saturated fatty acid in algae oil.

The conversion of the mono-unsaturated fatty acids in the algae oil are 81\% and 90\% for FA16:1 and FA18:1, respectively, and are therefore in the same range as from the ethenolysis of the model substrate mixture. Also, the conversion of the fivefold unsaturated fatty acid FA20:5 is again almost complete (92\%). The selectivities for the ethenolysis products of the mono-unsaturated fatty acids are between $83 \%$ and $97 \%$ and consistently high compared to the model substrate mixture. The selectivity for E6:1 is $82 \%$ and equals the result of the model substrate mixture. However, the selectivity of $64 \%$ for CHD as self-metathesis product is lower than the values observed with the model substrate mixture.

Overall, ethenolysis of $\mathrm{scCO}_{2}$ extracted algae oil in $\mathrm{scCO}_{2}$ proceeds with high conversions between $81 \%$ and $92 \%$ and high selectivities for ethenolysis products with exception of CHD formed by intramolecular self-metathesis of FA20:5.

\section{Butenolysis of model compounds and microalgae oil}

Besides ethenolysis, the cross-metathesis with internal alkenes such as 2-butene is a versatile tool to convert fatty acids to a wide spectrum of unsaturated compounds and gives access to products with chain lengths different to the ethenolysis pro-

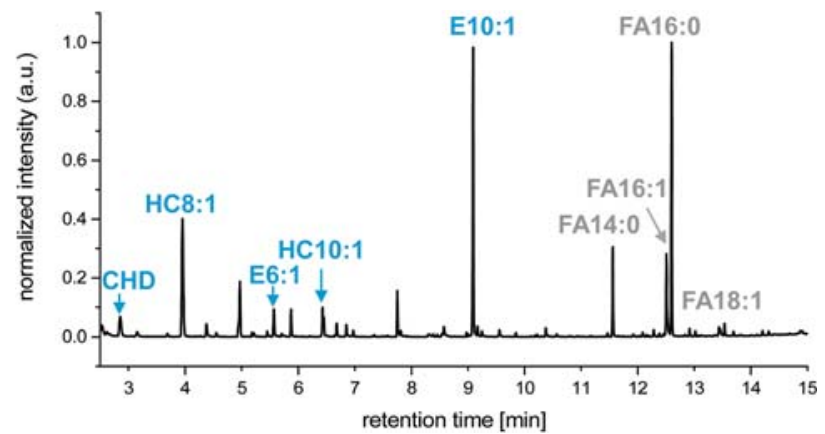

Fig. 4 Gas chromatogram of the ethenolysis of $\mathrm{scCO}_{2}$ extracted algae oil in $\mathrm{sCCO}_{2}$ (after transesterification with methanol) with HoveydaGrubbs $1^{\text {st }}$ generation catalyst and assignments of the ethenolysis products (HC8:1 1-octene, E6:1 methyl 5-hexenoate, HC10:1 1-decene, E10:1 methyl 9-decenoate), the self-metathesis product CHD 1,4-cyclohexadiene and the fatty acid esters (FA14:0 methyl myristate, FA16:1 methyl palmitoleate, FA16:0 methyl palmitate, FA18:1 methyl oleate). Other signals likely originate from side-products of ethyl vinyl ether quenching

ducts. While ethenolysis gives rise to products of mainly evennumbered hydrocarbon chains, butenolysis with 2-butene gives odd-numbered products. Furthermore, cross-metathesis with internal alkenes circumvents the specific disadvantage of ethenolysis: in the cross-metathesis with ethylene an unstable methylidene intermediate is formed which can lead to fast decomposition of the catalyst and therefore limited productivity. ${ }^{36-38}$

To establish the butenolysis in $\mathrm{scCO}_{2}$ as reaction medium, first the butenolysis of methyl oleate as a model compound was investigated. Hoveyda-Grubbs $2^{\text {nd }}$ generation catalyst was chosen as it gave better results in butenolysis reactions in organic solvent compared to Hoveyda-Grubbs $1^{\text {st }}$ generation catalyst. ${ }^{18,39,40}$ Similar to the aforementioned ethenolysis in $\mathrm{scCO}_{2}$, the butenolysis was conducted at a pressure of $300 \mathrm{bar}$ at a temperature of $45^{\circ} \mathrm{C}$.

Butenolysis of methyl oleate results in the formation of methyl 9-undecenoate E11:1 and 2-undecene HC11:1 (cf. Scheme 1, $\mathrm{R}=\mathrm{Me}$ ). Conditions similar to butenolysis in dichloromethane were adopted (10 equivalents of 2-butene and $0.1 \mathrm{~mol} \%$ Hoveyda-Grubbs $2^{\text {nd }}$ generation catalyst) ${ }^{18}$ which resulted in a conversion of methyl oleate of $93 \%$. Only small amounts of self-metathesis products (dimethyl 9-octadecendioate DE18:1 and 9-octadecene HC18:1) were formed. Selectivity for the desired butenolysis products was around 94\%. The butenolysis products were formed in a cis : trans ratio of about $20: 80$. All these results match with butenolysis of methyl oleate in dichloromethane as solvent. ${ }^{18,40}$ Upon decreasing the catalyst loading the selectivity was virtually unaffected whereas the conversion dropped to $82 \%$ at a catalyst loading of $0.05 \mathrm{~mol} \%$ and to $25 \%$ at a catalyst loading of $0.01 \mathrm{~mol} \%$, respectively (Table $\mathrm{S} 11 \dagger$ ). Compared to ethenolysis of methyl oleate in $\mathrm{scCO}_{2}$, the catalyst loading required for maximum butenolysis $(0.1 \mathrm{~mol} \%)$ is fivefold lower. As previously stated, the formation of the unstable methylidene intermediate cata- 
lyst species in the ethenolysis is presumably a major factor contributing to the necessity of a higher catalyst loading. In addition, the more reactive terminal double bond of the ethenolysis products can compete with the internal one of the starting material.

Again, first the simplified model substrate mixture was used. The following butenolysis products were expected (Scheme 3): 2-undecene HC11:1 and methyl 9-undecenoate E11:1 from FA18:1 and 2,5-heptadiene HC7:2, methyl 5-heptenoate E7:1 and 2-pentene HC5:1 formed from FA20:5. Note that complete butenolysis of FA20:5 can generate up to four equivalents of HC7:2. 2-Pentene HC5:1, the smallest butenolysis product of FA20:5, was not detected in GC analysis due to its low boiling point.

The same reaction conditions as for methyl oleate were adopted employing a catalyst loading of $0.1 \mathrm{~mol} \%$ HoveydaGrubbs $2^{\text {nd }}$ generation catalyst (referring to the number of double bonds). After two hours, GC analysis revealed almost complete conversion for FA20:5 and a conversion of 88\% for FA18:1. Butenolysis of FA18:1 proceeded in high selectivity (88\% for E11:1 and 84\% for HC11:1) whereas FA20:5 was converted somewhat less selective (HC7:2 52\% and E7:1 66\%). Incomplete butenolysis of FA20:5, leading to two-, three- and four-fold unsaturated products, can decrease the selectivity for E7:1 and HC7:2. Remarkably, the selectivity for the self-metathesis product CHD is only $27 \%$ and thus significantly lower compared to the corresponding ethenolysis experiment. Please note that the concentrations of 2-butene and ethylene differ. In the butenolysis a 10 -fold excess of 2-butene was applied, whereas in the ethenolysis experiments a 4-fold excess of ethylene was used.

Based on these results, butenolysis of $\mathrm{scCO}_{2}$ extracted algae oil (Table 2, column "scCO $\mathrm{C}_{2}$ extracted algae oil" and Fig. 5) was carried out applying the same reaction conditions $(0.1 \mathrm{~mol} \%$ catalyst, 300 bar $\mathrm{scCO}_{2}$ at $45{ }^{\circ} \mathrm{C}, 10$-fold excess of 2-butene). Besides 2-nonene HC9:1, 2-undecene HC11:1 and methyl 9-undecenoate E11:1 as butenolysis products from FA16:1 and FA18:1, respectively, methyl 5-heptenoate E7:1 and 2,5-heptadiene HC7:2 from FA20:5 were found. With 91\% and 99\% the conversions of FA18:1 and the five-fold unsaturated fatty FA20:5, respectively, agree with the conversions observed for the mixture of model compounds (Table 2). For FA16:1 a con-

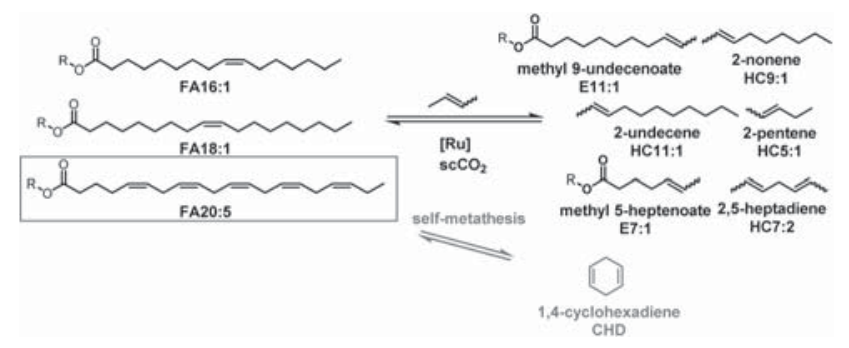

Scheme 3 Butenolysis products of the unsaturated fatty acids present in algae oil from Phaeodactylum tricornutum, and CHD as a self-metathesis product of FA20:5.
Table 2 Butenolysis of unsaturated fatty acids of a model substrate mixture and $\mathrm{sCCO}_{2}$ extracted algae oil with conversions of the components and selectivities for butenolysis products and the self-metathesis product 1,4-cyclohexadiene (CHD)

\begin{tabular}{lllc}
\hline & & $\begin{array}{l}\text { Model } \\
\text { substrate } \\
\text { mixture }\end{array}$ & $\begin{array}{l}\text { scCO }_{2} \\
\text { extracted } \\
\text { algae oil }\end{array}$ \\
\hline Composition of the initial reaction & FA14:0 & - & 9 \\
mixture $[\%]$ & FA16:1 & - & 47 \\
& FA16:0 & 40 & 25 \\
& FA18:1 & 50 & 8 \\
& FA18:0 & - & 1 \\
& FA20:5 & 10 & 10 \\
& & & \\
Conversion $^{b}[\%]$ & FA16:1 & - & 81 \\
& FA18:1 & 88 & 91 \\
& FA20:5 & 97 & $>99$ \\
& & & 24 \\
Selectivity $^{c}[\%]$ for & CHD & 27 & 55 \\
& HC7:2 & 52 & 65 \\
& E7:1 & 66 & 85 \\
& HC9:1 & - & 82
\end{tabular}

Conditions: $0.1 \mathrm{~mol} \%$ Hoveyda-Grubbs $2^{\text {nd }}$ generation catalyst, 10-fold excess of 2-butene, 300 bar $\mathrm{CO}_{2}$ (total pressure) at $45^{\circ} \mathrm{C}, 2 \mathrm{~h}$. Average of two independent experiments, $c f$. ESI for complete data. ${ }^{a}$ Mixture of 40\% FA16:0, 50\% FA18:1, 10\% FA20:5. ${ }^{b}$ Determined via FA16:0 as an internal standard. ${ }^{c}$ The selectivity to a product is defined as the ratio of the product to the theoretical maximum amount of this product at complete butenolysis or in case of CHD (1,4-cyclohexadiene) complete self-metathesis of FA20:5 (determined via FA16:0 as an internal standard) in the gas chromatograms.

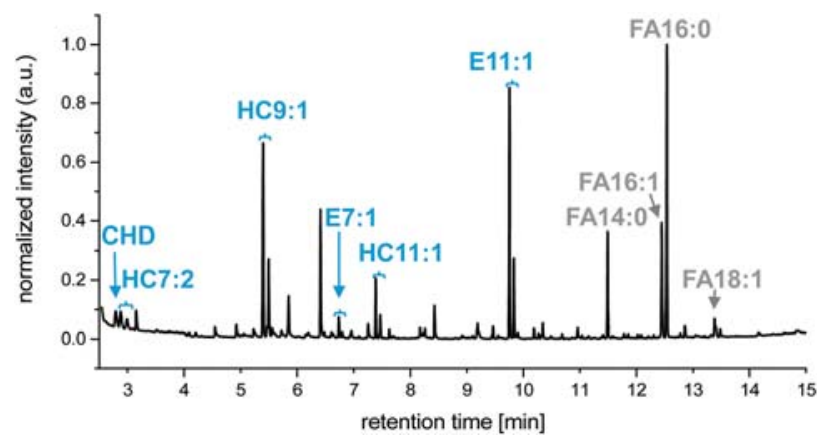

Fig. 5 Gas chromatogram of butenolysis in $\mathrm{scCO}_{2}$ of $\mathrm{scCO}_{2}$ extracted algae oil (after transesterification with methanol) with Hoveyda-Grubbs $2^{\text {nd }}$ generation catalyst and assignments of the butenolysis products (HC7:2 2,5-heptadiene, HC9:1 2-nonene, E7:1 methyl 5-heptenoate, HC11:1 2-undecene, E11:1 methyl 9-undecenoate) and the fatty acid esters (FA14:0 methyl myristate, FA16:1 methyl palmitoleate, FA16:0 methyl palmitate, FA18:1 methyl oleate). Other signals likely originate from side-products of ethyl vinyl ether quenching.

version of $81 \%$ was determined. The selectivities for the butenolysis products of the mono-unsaturated fatty acids are high (between 82 and $85 \%$ ) and in the same range as for methyl oleate as a single model component. Furthermore, the butenolysis products of FA20:5 are formed with selectivities comparable to the simplified model substrate mixture. 
All in all, in the butenolysis of $\mathrm{scCO}_{2}$ extracted algae oil high conversions and selectivities were achieved comparable to those obtained in the reactions with the neat model substances.

\section{Simultaneous extraction and cross-metathesis in $\mathbf{~ s c C O}_{2}$}

As demonstrated above, $\mathrm{scCO}_{2}$ is a powerful extraction medium for lipids of microalgae and is also a suitable reaction medium for cross-metathesis of this algae feedstock that is compatible with the ruthenium-based catalysts. In terms of reducing multiple reaction steps, avoiding solvent removal and integrating a direct valorization of the feedstock, we propose a combined approach of extraction and cross-metathesis of microalgae in $\mathrm{scCO}_{2}$.

The combination of extraction and ethenolysis or butenolysis was performed at a $\mathrm{scCO}_{2}$ pressure of 300 bar at $45^{\circ} \mathrm{C}$. For both catalytic transformations, $1 \mathrm{~g}$ of ultrasound pre-treated freeze-dried algae were placed in a high-pressure reactor together with the corresponding amount of the metathesis catalyst $\left(0.5 \mathrm{~mol} \%\right.$ of Hoveyda-Grubbs $1^{\text {st }}$ generation catalyst for ethenolysis and $0.1 \mathrm{~mol} \%$ Hoveyda-Grubbs $2^{\text {nd }}$ generation catalyst for butenolysis, respectively). In case of ethenolysis, 10 bar ethylene and for butenolysis, a 10-fold excess of 2-butene was applied.

Subjecting the freeze-dried algae to the combined extraction and ethenolysis results in a conversion of $32 \%$ and $44 \%$ (Table 3) for FA16:1 and FA18:1, respectively. In contrast, the

Table 3 Integrated procedure of extraction and cross-metathesis of freeze-dried algae in $\mathrm{scCO}_{2}$ with selectivities and conversions of the unsaturated fatty acids

\begin{tabular}{|c|c|c|c|c|}
\hline \multirow[b]{2}{*}{ Conversion $^{c}[\%]$} & \multicolumn{2}{|c|}{$\begin{array}{l}\text { Combined } \\
\text { extraction and } \\
\text { ethenolysis }{ }^{a} \text { of } \\
\text { freeze-dried algae }\end{array}$} & \multicolumn{2}{|c|}{$\begin{array}{l}\text { Combined } \\
\text { extraction and } \\
\text { butenolysis }{ }^{b} \text { of } \\
\text { freeze-dried algae }\end{array}$} \\
\hline & FA16:1 & 32 & FA16:1 & 47 \\
\hline & FA18:1 & 44 & FA18:1 & 65 \\
\hline & FA20:5 & 88 & FA20:5 & 89 \\
\hline \multirow[t]{6}{*}{ Selectivity $^{d}[\%]$ for } & CHD & 49 & CHD & 36 \\
\hline & HC5: $2^{e}$ & - & HC7:2 & 70 \\
\hline & E6:1 & 87 & E7:1 & 67 \\
\hline & HC8:1 & 60 & HC9:1 & 96 \\
\hline & HC10:1 & 88 & HC11:1 & 97 \\
\hline & E10:1 & 77 & E11:1 & 70 \\
\hline
\end{tabular}

The fresh algae were ultrasonicated and freeze-dried. The composition of fatty acids in the freeze-dried algae were assumed to be the same as for the $\mathrm{scCO}_{2}$ extracted algae oil. The reaction mixture was analyzed via gas chromatography after transesterification and filtration. Average of two independent experiments, $c f$. ESI for complete data. ${ }^{a}$ Conditions: $0.5 \mathrm{~mol} \%$ Hoveyda-Grubbs $1^{\text {st }}$ generation catalyst, 10 bar ethylene, 300 bar $\mathrm{CO}_{2}$ (total pressure) at $45{ }^{\circ} \mathrm{C}, 18 \mathrm{~h}$. ${ }^{b}$ Conditions: $0.1 \mathrm{~mol} \%$ Hoveyda-Grubbs $2^{\text {nd }}$ generation catalyst, 10 fold-excess of 2-butene, 300 bar $\mathrm{CO}_{2}$ (total pressure) at $45{ }^{\circ} \mathrm{C}, 3 \mathrm{~h}$. ${ }^{c}$ Conversions were determined via gas chromatography via the FA16:0 present in the algae oil as an internal standard. ${ }^{d}$ The selectivity for a product is defined as the ratio of the product to the theoretical maximum amount of this product at complete ethenolysis or butenolysis or in case of CHD (1,4-cyclohexadiene) complete self-metathesis of FA20:5 (determined over FA16:0 as an internal standard) in GC. ${ }^{e}$ Not detectable via GC due to its low boiling point. conversion of the fivefold unsaturated fatty acid FA20:5 is higher with $88 \%$.

In comparison to the two-step procedure the conversions in this combined approach differ significantly. While the conversion of the poly-unsaturated fatty acid FA20:5 is almost identical (88\% for combined and $92 \%$ for two-step approach), the mono-unsaturated fatty acids FA16:1 and FA18:1 are converted to a much lower extent. This might be due to a slow extraction over the duration of the experiment, such that the extracted fatty acids are not exposed to the catalyst over the entire experiment. One reason for this are different high-pressure setups. In the combined approach the algae oil is extracted by means of a static $\mathrm{scCO}_{2}$ batch reactor, whereas in the two-step process the algae oil is extracted under a continuous flow. Furthermore, reaction conditions had to be adopted to the limited thermal stability of the Ru catalyst and were not ideal for a maximum yield of extracted oil.

However, the selectivities in the combined approach are comparable to the two-step procedure. The selectivities for the ethenolysis products of the mono-unsaturated fatty acids in the combined approach are between 60 and $88 \%$ and in the two-step procedure between 83 and $97 \%$. Also, for the polyunsaturated fatty acid FA20:5 the selectivities for the ethenolysis product E6:1 (87\%) and for the self-metathesis product CHD (49\%) are comparable to the extraction and separate metathesis. All in all, the characteristic selectivity of the catalyst is evidently not affected by components of the freeze-dried algae.

In the combined extraction and butenolysis of pre-treated freeze-dried algae (Table 3) again lower conversions of the monounsaturated fatty acids were observed. Conversions of $47 \%$ and 65\% were found for FA16:1 and FA18:1, respectively. The conversion of the poly-unsaturated fatty acid FA20:5 of 89\% is still in the same range as for the butenolysis two-step process.

The desired butenolysis products of the mono-unsaturated fatty acids FA16:1 and FA18:1 are formed with selectivities between 70 and $97 \%$. For E7:1 a selectivity of $67 \%$ is observed. These are again in accordance with the two-step approach.

The conformity of trends in conversions in ethenolysis and butenolysis, respectively, in the combined approaches shows that the combination of extraction and catalytic transformation in one batch reactor is feasible but requires optimization in terms of extraction. However, it is important to note that this integrated one-pot approach shows comparable selectivities for the desired higher-value chemicals in relation to the step-wise approach of extraction and catalysis, and therefore, makes this a promising concept to overcome the typical bottleneck of extraction in the valorization of biomass.

\section{Alkoxycarbonylation}

To further illustrate the concept of integrated $\mathrm{scCO}_{2}$ extraction and functionalization of fatty acids from microalgae, isomerizing alkoxycarbonylation was studied as another catalytic transformation system that enables the upgrading of algae oil into higher value chemical intermediates. This converts an internal double bond into a terminal ester group by reaction with methanol and CO. Pd(II) catalysts with a sterically demanding 
diphosphine ligand such as $\left[\mathrm{Pd}(\mathrm{dtbpx})(\mathrm{OTf})_{2}\right](\mathrm{dtbpx}=1,2$-bis ((di-tert-butylphosphino) methyl)benzene) convert unsaturated fatty acid esters such as methyl oleate to linear long-chain $\alpha, \omega$-diesters with high linear selectivities $(>90 \%){ }^{41,42}$ As demonstrated previously, mid-chain (di-)carboxylic acid esters, currently only accessible via demanding synthetic routes, can be obtained in a two-step fully catalytic route by butenolysis and subsequent isomerizing alkoxycarbonylation without prior work-up and purification. ${ }^{18}$ Thus, in order to prove the feasibility of a bio-refinery concept starting from crude microalgae biomass, $\mathrm{scCO}_{2}$ extraction was combined with isomerizing alkoxycarbonylation.

Using methyl oleate as model compound, the isomerizing alkoxycarbonylation was performed at $90{ }^{\circ} \mathrm{C}$ and 30 bar $\mathrm{CO}$ pressurized with $\mathrm{CO}_{2}$ to a total pressure of 325 bar with additional methanol. As a catalyst system $0.8 \mathrm{~mol} \%$ [Pd(dtbpx) $\left.(\mathrm{OTf})_{2}\right]$ and $4 \mathrm{~mol} \%\left(\mathrm{dtbpxH}_{2}\right)(\mathrm{OTf})_{2}$ was used. After $18 \mathrm{~h}$, a conversion of $29 \%$ was observed which is lower than expected under standard conditions applying pure methanol as solvent. ${ }^{41,43}$ This is due to the low nucleophile concentration which is rate determining. ${ }^{44}$ Yet the high selectivity for the linear product (92\%) was not affected.

The isomerizing alkoxycarbonylation of $\mathrm{ScCO}_{2}$ extracted algae oil under identical conditions (but with a reaction time of $96 \mathrm{~h}$, affording a conversion of 50\%) again, proceed with high selectivities around 90\% for both, the linear 1,19-diester from FA18:1 and the linear 1,17-diester from FA16:1.

Also, in the one-pot combination of extraction and isomerizing alkoxycarbonylation of the lipids from freeze-dried algae, the fatty acids were converted to the desired linear diester with selectivities over 90\%. Overall, these findings underline the viability of this reaction in supercritical $\mathrm{CO}_{2}$.

\section{Conclusions}

An integration of biomass extraction and catalytic upgrading in supercritical $\mathrm{CO}_{2}$ as a solvent allows for a more straightforward utilization of microalgae biomass as a source of chemical intermediates. The desired lipids are extracted selectively and converted in a one-pot approach by catalytic olefin ethenolysis or butenolysis, respectively, to target mid-chain olefins and unsaturated esters. These olefin metathesis in $\mathrm{ScCO}_{2}$ proceed with high conversions and selectivities. In addition to its advantageous selectivity as a solvent, $\mathrm{CO}_{2}$ is benign and easy to remove from the products.

The approach of integrated extraction and catalytic upgrading of lipids, demonstrated here for the case of olefin metathesis and isomerizing carbonylation, can help to overcome the bottleneck biomass extraction represents for its utilization as a feedstock, and of microalgae in particular.

\section{Conflicts of interest}

There are no conflicts to declare.

\section{Acknowledgements}

D. P. gratefully acknowledges a Zukunftskolleg Marie-Curie Incoming Fellowship for funding. Financial support by the Konstanz Research School of Chemical Biology through a graduate fellowship is gratefully acknowledged by S. K. H. Funding by the BMBF (INTEXCAT, 031B0676) is acknowledged. We thank Heiko Wagner of Christian Wilhelms' group at the University of Leipzig for providing access and kind assistance with microplate FT-IR analysis.

\section{Notes and references}

1 Y. Chisti, Biotechnol. Adv., 2007, 25, 294-306.

2 S. K. Hess, B. Lepetit, P. G. Kroth and S. Mecking, Eur. J. Lipid Sci. Technol., 2018, 120, 1700152.

3 Y. Zhu, C. Romain and C. K. Williams, Nature, 2016, 540, 354.

4 C. Ratledge, $O C L, 2013,20$, D602.

5 U. Biermann, U. Bornscheuer, M. A. R. Meier, J. O. Metzger and H. J. Schäfer, Angew. Chem., Int. Ed., 2011, 50, 38543871.

6 A. M. Aliev and I. M. Abdulagatov, J. Mol. Liq., 2017, 239, 96-100.

7 H. Taher, S. Al-Zuhair, A. H. Al-Marzouqi, Y. Haik, M. Farid and S. Tariq, J. Supercrit. Fluids, 2014, 86, 57-66.

8 R. L. Mendes, J. P. Coelho, H. L. Fernandes, I. J. Marrucho, J. M. S. Cabral, J. M. Novais and A. F. Palavra, J. Chem. Technol. Biotechnol., 1995, 62, 53-59.

9 R. L. Mendes, B. P. Nobre, M. T. Cardoso, A. P. Pereira and A. F. Palavra, Inorg. Chim. Acta, 2003, 356, 328-334.

10 J. Lorenzen, N. Igl, M. Tippelt, A. Stege, F. Qoura, U. Sohling and T. Brück, Bioprocess Biosyst. Eng., 2017, 40, 911-918.

11 E. Tommasi, G. Cravotto, P. Galletti, G. Grillo, M. Mazzotti, G. Sacchetti, C. Samorì, S. Tabasso, M. Tacchini and E. Tagliavini, ACS Sustainable Chem. Eng., 2017, 5, 83168322.

12 W. Leitner, C. R. Acad. Sci., Ser. IIc: Chim., 2000, 3, 595-600.

13 M. D. Lundin, A. M. Danby, G. R. Akien, T. P. Binder, D. H. Busch and B. Subramaniam, ACS Sustainable Chem. Eng., 2015, 3, 3307-3314.

14 D. Guironnet, I. Göttker-Schnetmann and S. Mecking, Macromolecules, 2009, 42, 8157-8164.

15 P. G. Jessop, T. Ikariya and R. Noyori, Chem. Rev., 1999, 99, 475-494.

16 W. Leitner, Acc. Chem. Res., 2002, 35, 746-756.

17 S. Chikkali and S. Mecking, Angew. Chem., Int. Ed., 2012, 51, 5802-5808.

18 J. Zimmerer, L. Williams, D. Pingen and S. Mecking, Green Chem., 2017, 19, 4865-4870.

19 A. Fürstner, D. Koch, K. Langemann, W. Leitner and C. Six, Angew. Chem., Int. Ed. Engl., 1997, 36, 2466-2469.

20 A. Fürstner, L. Ackermann, K. Beck, H. Hori, D. Koch, K. Langemann, M. Liebl, C. Six and W. Leitner, J. Am. Chem. Soc., 2001, 123, 9000-9006. 
21 X. Hu, M. T. Blanda, S. R. Venumbaka and P. E. Cassidy, Polym. Adv. Technol., 2005, 16, 146-149.

22 T. Tonon, D. Harvey, T. R. Larson and I. A. Graham, Phytochemistry, 2002, 61, 15-24.

23 Density of neat carbon dioxide at the given temperatures and pressures were determined according to https:// webbook.nist.gov/chemistry/fluid/.

24 C. Crampon, O. Boutin and E. Badens, Ind. Eng. Chem. Res., 2011, 50, 8941-8953.

25 J. M. Bermúdez Menéndez, A. Arenillas, J. Á. Menéndez Díaz, L. Boffa, S. Mantegna, A. Binello and G. Cravotto, J. Chem. Technol. Biotechnol., 2014, 89, 1779-1784.

26 J. Folch, I. Ascoli, M. Lees, J. A. Meath and F. N. LeBaron, J. Biol. Chem., 1951, 191, 833-841.

27 A. Ventrella, L. Catucci, G. Mascolo, A. Corcelli and A. Agostiano, Biochim. Biophys. Acta, 2007, 1768, 16201627.

28 T. Mock and B. M. A. Kroon, Phytochemistry, 2002, 61, 4151.

29 B. Lepetit, S. Sturm, A. Rogato, A. Gruber, M. Sachse, A. Falciatore, P. G. Kroth and J. Lavaud, Plant Physiol., 2013, 161, 853-865.

30 H. Wagner, Z. Liu, U. K. Langner, K. Stehfest and C. Wilhelm, J. Biophotonics, 2010, 3, 557-566.

31 R. L. Mendes, A. D. Reis and A. F. Palavra, Food Chem., 2006, 99, 57-63.
32 A. D. Ivahnov, T. E. Skrebets and K. G. Bogolitsyn, Russ. J. Phys. Chem. B, 2016, 10, 1244-1247.

33 J. A. Hyatt, J. Org. Chem., 1984, 49, 5097-5101.

34 J. Song, M. Hou, G. Liu, J. Zhang, B. Han and G. Yang, J. Phys. Chem. B, 2009, 113, 2810-2814.

35 D. Pingen, J. Zimmerer, N. Klinkenberg and S. Mecking, Green Chem., 2018, 20, 1874-1878.

36 K. A. Burdett, L. D. Harris, P. Margl, B. R. Maughon, T. Mokhtar-Zadeh, P. C. Saucier and E. P. Wasserman, Organometallics, 2004, 23, 2027-2047.

37 S. E. Lehman and K. B. Wagener, Organometallics, 2005, 24, 1477-1482.

38 M. S. Sanford, J. A. Love and R. H. Grubbs, J. Am. Chem. Soc., 2001, 123, 6543-6554.

39 J. Patel, J. Elaridi, W. R. Jackson, A. J. Robinson, A. K. Serelis and C. Such, Chem. Commun., 2005, 5546-5547.

40 J. Patel, S. Mujcinovic, W. R. Jackson, A. J. Robinson, A. K. Serelis and C. Such, Green Chem., 2006, 8, 450-454.

41 C. Jiménez-Rodriguez, G. R. Eastham and D. J. ColeHamilton, Inorg. Chem. Commun., 2005, 8, 878-881.

42 P. Roesle, C. J. Dürr, H. M. Möller, L. Cavallo, L. Caporaso and S. Mecking, J. Am. Chem. Soc., 2012, 134, 17696-17703.

43 V. Goldbach, M. Krumova and S. Mecking, ACS Catal., 2018, 8, 5515-5525.

44 V. Goldbach, L. Falivene, L. Caporaso, L. Cavallo and S. Mecking, ACS Catal., 2016, 6, 8229-8238. 